\title{
Sequence of implantation and fetal and placental weights in the rat
}

\author{
Kerry Herbert and N. W. Bruce \\ Department of Anatomy and Human Biology, University of Western Australia, Nedlands, \\ Western Australia, 6009
}

\begin{abstract}
Summary. Rats (30) were injected intravenously with Evans blue dye on Day 5 of gestation and their uteri were examined to determine the position of early implantations. On Day 7 they were examined again for late implantations. Fetal sex and fetal and placental weights were determined at Day 22 (15 rats). The distribution of the $20 \%$ early implantations appeared random with respect to position in the uterine horn. There was no difference in fetal weight, placental weight or sex ratio between early and late implanting embryos.
\end{abstract}

\section{Introduction}

Little attention has been paid to the possibility that birthweight is influenced by environmental factors acting early in gestation. In the rat, a number of factors affect fetal weight, including fetal sex (Bruce \& Norman, 1975), litter size and fetal position in the uterine horn (Barr, Jensh \& Brent, 1970). The fetal position effect, whereby the fetus nearest the ovary is lighter than the remainder in the uterine horn, is evident as early as Day 13 (Norman \& Bruce, 1979a). Much of the variation in fetal weight within litters, however, remains unexplained. The present work was carried out to determine whether the sequence in which blastocysts implant in the uterus affects their subsequent growth.

\section{Materials and Methods}

Nulliparous albino Wistar rats, 3-5 months old and weighing $213 \pm 1$ g (s.e.m.) at mating, were used. The rats came from a closed breeding colony maintained for 20 years. They were kept in an environmentally controlled building: lights were on from 07:00 to 21:00 h. The 30 females were caged with males overnight and the day on which spermatozoa were found in a vaginal smear was called Day 1 of gestation: rats from this colony normally litter on the morning of Day 23.

All mated rats were examined on Days 5 and 7 of gestation to determine the sequence of implantation. Half of the rats were also examined on Day 22 to determine fetal sex and fetal and placental weights. The Day 5 examination was carried out between 14:00 and 18:00 h. Each rat was anaesthetized with ether and $0.2 \mathrm{ml}$ of a $1 \%$ Evan's blue solution was injected into a saphenous vein. After $10 \mathrm{~min}$, a ventral mid-line laparotomy was performed and the uterine horns were examined with a dissection microscope. Small blue spots, resulting from increased permeability of the decidual region (Psychoyos, 1971), were classed as 'early implantations'. The position of each was recorded and India ink was scratched lightly over the antimesometrial aspect of the perimetrium immediately adjacent to the implantation for later identification. The 
laparotomy incision was then closed and the rat allowed to recover. On Day 7, between 09:00 and 12:00 h, a second laparotomy was performed. At this time, conceptuses were clearly evident as small swellings in the uterine wall and were numbered consecutively in each horn with the first being that closest to the ovarian end. Conceptuses not associated with an ink mark were classed as 'late implantations'. Out of a total of 82 ink marks, 5 were not adjacent to a conceptus at Day 7 and so were classed as false positives and excluded from later calculations. For the Day 22 examination, each rat was killed with an overdose of sodium pentobarbitone between 09:00 and 12:00 h. The uterus was removed and fetuses and placentas were examined and weighed (Norman \& Bruce, 1979b).

Standard statistical methods were used: fetal position, fetal sex and fetal mortality data were analysed by contingency tests and fetal and placental weights by paired $t$ tests (Snedecor \& Cochran, 1967). Weights of female fetuses were multiplied by 1.054 to approximate those of males before statistical comparisons were made: placentas were not adjusted since there is little weight difference between the sexes in this variable (Bruce \& Norman, 1975).

\section{Results}

The 30 rats examined on Days 5 and 7 of gestation had an average of $13.13 \pm 0.44$ (s.e.m.) implantations of which $2.57 \pm 0.27(20 \%)$ were classed as early and $10.57 \pm 0.51$ as late. There was no evidence that the frequency distribution differed significantly between positions along the uterine horn (Table 1) $\left(2 \times 10\right.$ contingency test: $\left.\chi^{2}=8 \cdot 2\right)$, nor was the frequency of early implantations at position $1(17 \%)$ significantly different $\left(2 \times 2\right.$ contingency test: $\left.\chi^{2}=1 \cdot 34\right)$ from that in the remainder of the uterine horn $(27 \%)$.

Table 1. The frequency of early and late implantations according to position in the uterine horn $(\mathrm{N}=46)$ of the rat

\begin{tabular}{lrrrrrrrrrr}
\hline & \multicolumn{10}{c}{ Position in horn* } \\
\cline { 2 - 11 } & 1 & 2 & 3 & 4 & 5 & 6 & 7 & 8 & 9 & 10 \\
\hline No. of early implantations ${ }^{\dagger}$ & 8 & 15 & 11 & 13 & 9 & 9 & 9 & 1 & 2 & 0 \\
No. of late implantations & 38 & 31 & 35 & 30 & 31 & 25 & 16 & 14 & 6 & 1 \\
Early implantations (\% of total) & 17 & 33 & 24 & 30 & 22 & 26 & 36 & 7 & 25 & 0 \\
\hline
\end{tabular}

* Position 1 is that nearest the ovary.

† Identified on Day 5 of gestation with Evans blue dye.

$\ddagger$ Identified at laparotomy on Day 7.

The 15 rats examined on Day 22 had an average of $8.20 \pm 0.67$ live and $3.73 \pm 0.61$ dead fetuses in the 16 uterine horns used for analysis. The remaining horns were excluded since they did not contain both early and late live fetuses ( 9 horns), or because fetal mortality was greater than $50 \%$ ( 5 horns) and was associated with uterine adhesions which may have affected weights of the survivors. The difference in mean weight between early and late implantations was determined for each horn and the average difference tested for significance by paired $t$ tests: there were no significant differences for fetal weight adjusted for sex $(4.332 \pm 0.079$ and 4.350 $\pm 0.075 \mathrm{~g})$ or placental weight $(0.436 \pm 0.011$ and $0.450 \pm 0.009 \mathrm{~g})$ of implantations that had been early and late respectively. Similar comparisons of fetal weight with male and female fetuses treated separately again revealed no significant differences between early and late implantations. Furthermore, there was no evidence that the male:female sex ratio differed for early $(12: 14)$ and late $(25: 23)$ implantations. The procedure of marking early implantations 
with India ink did not appear to affect their mortality rate which was $28 \%$ compared to $32 \%$ for the late implantations. Fetuses and placentas at the ovarian end of the uterine horn were $2.5 \%$ and $3.1 \%$ lighter, respectively, than those in the remainder of the horn but neither result was significant.

\section{Discussion}

The aim of the present study was to relate an early event, i.e. sequence of implantation, to subsequent fetal growth, fetal sex and position in the uterine horn. In practice, a reliable distinction could only be made between early implantations detected by Evans blue uptake on Day 5, and late implantations visible on Day 7. Estimation of the extent and intensity of dye uptake was considered too subjective to justify further subdivision. Within this constraint, however, the proportion of implantations in each group could be partly controlled by the time selected for the Day 5 examination. In the present work, an early :late implantation ratio of $1: 4$ was obtained and so, in general, the characteristics of the first embryo to implant in each uterine horn could be compared to those of the remainder.

The major question examined was whether early implantations would develop into heavier fetuses and be associated with heavier placentas near term. This was considered likely in view of the following. Firstly, early implantation might be a feature of the more mature and faster growing conceptuses. Secondly, the first implantations might be at more favourable sites and the embryos would enjoy a continuing environmental advantage over their neighbours. Thirdly, early implanting embryos might have an effectively longer period of growth between implantation and the Day 22 examination. If growth curves were parallel, then a small difference in implantation time would result in an appreciable difference in fetal weight at Day 22 when the rate of fetal growth is rapid.

The finding that early and late implanting embryos did not differ in fetal or placental weight at Day 22 was thus unexpected and fails to support any of the above hypotheses. If there is a difference in development between early and late implanting embryos, subsequent growth seems to be adjusted to diminish this difference by term. It is just possible that the operative procedures selectively affected the early implantations but this is unlikely because their mortality rate was similar to that of the late implantations.

The possibility that conceptuses of one sex tend to implant before those of the other was also examined. Male fetuses are heavier than female fetuses near term (Bruce \& Norman, 1975) and it was thought that this might reflect a difference in their time of implantation. Furthermore, Ounsted (1972) had argued that male conceptuses have a greater antigenic dissimilarity to their mothers than have female conceptuses and this might also affect their time of implantation. However, the present results do not support these possibilities.

It has been postulated that the position in the uterine horn effect, which is clearly evident by Day 13 (Norman \& Bruce, 1979a), might be partly due to a delay in implantation at the position nearest the ovary. On the other hand, Psychoyos (1971) and others (see McLaren \& Michie, 1959) have suggested that implantation probably occurs at the ovarian end first, but no reliable evidence has been presented previously. The present work suggests that the first embryos to implant in the rat have little, if any, preference for a particular site and so are unlikely to be the cause of the position in the uterine horn effect.

It is concluded that the time of implantation has little influence over subsequent growth of conceptuses in the rat and does not appear to be related to the sex of the conceptus or to site within the uterine horn.

We are very grateful to Mr S. Parkinson for technical assistance. 


\section{References}

Barr, M., Jr, Jensh, R.P. \& Brent, R.L. (1970) Prenatal growth of the albino rat: effects of number, intrauterine position and resorptions. Am. J. Anat. 128, 413-428.

Bruce, N.W. \& Norman, N. (1975) Influence of sexual dimorphism on foetal and placental weights in the rat. Nature, Lond. 257, 62-63.

McLaren, A. \& Michie, D. (1959) The spacing of implantations in the mouse uterus. Mem. Soc. Endocr. 6, 65-75.

Norman, N.A. \& Bruce, N.W. (1979a) Fetal and placental weight relationships in the rat at Days 13 and 17 of gestation. J. Reprod. Fert. 57, 345348.
Norman, N.A. \& Bruce, N.W. (1979b) Fetal and placental weight relationships in the albino rat near term. Teratology 19, 245-250.

Ounsted, M. (1972) Gender and intrauterine growth. In Gender Differences: Their Ontogeny and Significance, pp. 177-201. Eds C. Ounsted \& D. C. Taylor. Churchill Livingstone, Edinburgh.

Psychoyos, A. (1971) Methods for studying changes in capillary permeability of the rat endometrium. In Methods in Mammalian Embryology, pp. 334-338. Ed. J. C. Daniel, Jr. W. H. Freeman, New York.

Snedecor, G.W. \& Cochran, W.G. (1967) Statistical Methods, 6th edn, pp. 238-240. Iowa State University Press, Ames.

Received 31 October 1979 